\title{
El debate epistemológico en torno a la teoría del diseño inteligente: la intervención de Stephen Meyer
}

\section{The Epistemological Debate about the Theory of Intelligent Design: the Intervention of Stephen Meyer}

\author{
Juan Eduardo Carreño Pavez \\ Universidad de los Andes, Chile \\ jedocarreno@gmail.com \\ Recibido: 05/09/2012 · Aceptado: 28/11/2013
}

\begin{abstract}
Resumen
La teoría del diseño inteligente tuvo una génesis controvertida, lo que ha marcado decisivamente el discurso de sus autores representativos. En este debate han sido Michael Behe y William Dembski quienes han recibido mayor atención, en tanto que otros autores de la corriente han pasado más bien desapercibidos. Este es el caso de Stephen Meyer, uno de los pocos teóricos del diseño que ha configurado una propuesta epistemológica articulada en relación con la teoría en cuestión. Presentamos aquí los aspectos fundamentales de su propuesta, junto a una valoración crítica de la misma.
\end{abstract}

Palabras clave: demarcación, diseño inteligente, epistemología, evolución, Meyer.

\section{Abstract}

The theory of intelligent design had a controversial genesis, which has actively influenced the work of its significant authors. In this debate, contributions by Michael Behe and William Dembski received more attention, while other authors have gone rather unnoticed. This is the case of Stephen Meyer, one of the few design theorists who has defended an articulated position regarding the epistemological status that would correspond to the theory. We present the fundamental aspects of the epistemological proposal of this author, along with a critical review of it.

Keywords: Demarcation, Epistemology, Intelligent Design, Meyer, Theory of Evolution. 
Introducción

Hace algunos años, un grupo de académicos del medio anglosajón introdujo una colección de propuestas destinadas a acabar con lo que concebían como una hegemonía tiránica del naturalismo metafísico en el ámbito de las ciencias naturales. El antecedente de esta nueva iniciativa se asocia al nombre del abogado y profesor de derecho Phillip E. Johnson, quien ve en las explicaciones darwinistas recogidas en textos de divulgación como The BlindWatchmaker, de Richard Dawkins, argumentos más propios de la retórica jurídica que del ámbito científico (Dawkins, 1996). Estas observaciones lo conducen a escribir y publicar en 1991 su conocido Darwin on Trial, una obra en la que se propone llevar a juicio, en términos figurativos, las argumentaciones esgrimidas por los darwinistas al defender sus posiciones (Johnson, 1993; 1998; 2002).

El desarrollo y madurez de lo que posteriormente se conocería como Teoría del Diseño Inteligente (TDI) puede situarse en el segundo lustro de la década del 90, con la publicación, en 1996, de la obra Darwin's Black Box (2006), del bioquímico, investigador y profesor de la Universidad de Lehigh, Michael Behe. Este autor pretende superar el tono controversial y polemista que caracteriza la obra de Johnson, para desarrollar una agenda propositiva y mucho más ambiciosa; en lugar de arremeter simplemente contra una interpretación de la historia de la vida en clave darwinista, el propósito declarado de Behe es el dar forma a una propuesta teórica capaz de englobar en una síntesis más amplia los hallazgos y aportes de la teoría sintética y de otros modelos evolutivos. En opinión de este autor, la biología de la última centuria ha mostrado, más allá de toda duda, la existencia de lo que denomina como "sistemas irreductiblemente complejos" (Behe, 2009: 428). Se trata de ensamblajes de componentes materiales cuya funcionalidad depende estrictamente de su integridad estructural. Behe ilustra este concepto mediante la 
imagen de la trampa de ratón; para que este artefacto desempeñe efectivamente su función de atrapar y eliminar roedores, es necesario que todos sus elementos se encuentren presentes y en la disposición adecuada o, de lo contrario, simplemente no hay trampa de ratón (Behe, 2006: 195-196).

De acuerdo con Behe, los sistemas irreductiblemente complejos no son una exclusividad del orden del fieri humano, sino que están presentes también en la naturaleza, siendo el flagelo bacteriano, el sistema de la coagulación de organismos homeotermos, y algunas partes del sistema inmunológico de organismos superiores sus ejemplos más notorios. En todos ellos hay un número de componentes - esto es, una «complejidad»-cuya interrelación es un requisito para que el conjunto desempeñe su función fisiológica; si falta uno de ellos, no hay menor función, simplemente no la hay (Behe, 2009: 429). De ello se sigue, según Behe, que la existencia de estos sistemas no puede ser explicada mediante los recursos de la teoría de la evolución por selección natural, según la cual todo órgano y parte de los seres vivos se ha formado gradualmente bajo la presión selectiva del entorno (Gould, 2004: 165-166). En efecto, en las etapas previas a su ordenación definitiva, un tal sistema en vías de formación no serviría para nada, y la mentada selección se encargaría de desechar todo rudimento. La alternativa de un ensamblaje simultáneo de todos los elementos tampoco es una alternativa verosímil, dadas las probabilidades francamente desfavorables que tal evento exige. Por ello, estos sistemas resultan «irreductibles» a las explicaciones evolutivas tradicionales. Desde estas coordenadas, el autor concluye que sistemas como los mencionados sólo pueden ser el producto de un diseño, entendiendo este concepto como "el arreglo de partes con vistas a un fin" (Behe, 2006: 193).

Es importante destacar aquí dos aspectos de la hipótesis de Michael Behe. El primero guarda relación con la identidad del diseñador de los sistemas "irreductiblemente complejos" que el autor detecta en la naturaleza. Behe insiste en sostener que la inferencia de diseño es un proceso lógico ordinario y común en nuestras vidas, y que por ello, la TDI no busca introducir presupuestos metafísicos de ninguna clase en el seno de la ciencia. Por ello, según este teórico del 
diseño, la naturaleza del diseñador no formaría parte del espectro de cuestiones que puedan tratarse en la propuesta, que como tal es científica y no filosófica. ${ }^{1}$ Pero esta aparente prudencia, sin embargo, deja el paso a posiciones ambiguas y menos mesuradas, en las que las pretensiones de la TDI parecen bastante más ambiciosas, llegando a sostener que la ciencia no debe tratar del problema de la identidad del diseñador hasta que esté preparada para hacerlo. ${ }^{2}$ Como se infiere de las afirmaciones, la posibilidad de que la TDI pueda llegar a la identificación del diseñador, a los ojos de Behe, no puede ser excluida. La segunda arista de la postura de Behe que conviene tener en cuenta es la de su relación con las teorías evolutivas, que describe no en términos de conflicto, sino de complementariedad. Adelantándose a las objeciones de sus detractores, Behe sostiene que la TDI no excluye la realidad de la evolución, ni del mecanismo neodarwinista en particular. La suya sería una teoría más amplia, pues habría en ella lugar para las explicaciones naturalistas tradicionales, siendo el diseño una modalidad explicativa de exclusión, esto es, una conclusión sostenible sólo cuando las teorías evolutivas tradicionales se muestran incapaces de reconstruir el surgimiento de un aspecto determinado de la naturaleza (Behe, 2009: 429).

Otra figura señera en la configuración de la TDI ha sido el matemático y filósofo William Dembski, cuyos esfuerzos se han centrado en la formalización y depuración lógica de la inferencia de diseño, y en la refutación de los ataques que la TDI ha recibido en el fragor de los debates que se han generado en torno a ella en la sociedad norteamericana (Dembski, 1998a; 1998b; 2004). Tal y como su predecesor, Dembski se adhiere a la tesis de la cotidianeidad de la inferencia de diseño, pero por ese mismo motivo, ve la necesidad

1 "La conclusión de que algo ha sido diseñado puede llevarse a cabo independientemente del conocimiento del diseñador. Como regla de procedimiento, el diseño debe ser primero aprehendido antes de que se plantee cualquier pregunta adicional sobre el diseñador. La inferencia de diseño puede ser mantenida con toda la firmeza posible en este mundo, sin saber nada del diseñador" (Behe, 2006: 197).

2 "Identificar el diseñador con métodos científicos puede ser extremadamente difícil. [...] Cuando una pregunta es demasiado difícil para la ciencia como para tratarla inmediatamente, es felizmente olvidada mientras otra pregunta más accesible es investigada" (Behe, 2006: 251). 
de someterla a una depuración y formalización que permita su integración en el quehacer científico. Enfrentados a un evento -afirma este autor- debemos optar entre tres modos mutuamente excluyentes y exhaustivos de explicación, a saber: la ley, el azar y el diseño. En el primer caso, el evento tendrá lugar casi siempre, dadas ciertas condiciones; en el segundo, la ocurrencia del evento quedará caracterizada por una distribución de probabilidad; el tercero, en fin, es una conclusión de descarte, sólo sostenible una vez eliminados los dos anteriores. ${ }^{3}$ Se trata de un procedimiento utilizado de un modo laxo o «preteórico» por diversas disciplinas, ${ }^{4}$ pero que también puede ser formulado como un criterio riguroso, que es lo que sustenta su conocido «filtro explicatorio», un algoritmo probabilístico muy citado entre los adherentes de la TDI. ${ }^{5}$

Respecto de la naturaleza del diseñador, Dembski acusa un vaivén análogo al de Behe. Ciertamente, por momentos este autor se muestra cauto, calificando a la TDI como "teológicamente minimalista” (Dembski, 1998a: 17), en cuanto no tiene por objetivo hacer afirmaciones acerca de la naturaleza del diseñador; esta actitud contrasta fuertemente con lo que tan sólo un par de páginas antes escribe Dembski, cuando se refiere no ya a un diseñador, sino abierta y francamente a Dios, y la posibilidad de conocer su interacción con el mundo mediante los métodos de las ciencias naturales (Dembski, 1998a: 15). La conocida mención que hace del cristianismo y de la creación en el mismo texto, junto a la crítica nada mesurada que introduce acerca de lo que concibe como un naturalismo metafísico que contamina las teorías evolutivas, han acabado por sellar el destino de su trabajo y de toda la TDI, que para estos efectos es tratada de modo unitario por sus muchos detractores. Aquellos han visto en este modelo una reiteración de los argumentos del desacreditado

3 El orden se debería al principio de la parsimonia, pues según Dembski, las explicaciones basadas en leyes son más simples que las que recurren al azar, y éstas, por su parte, más simples que las que introducen el diseño (Dembski, 1998b: 100).

4 Entre ellas, Dembski cuenta las disciplinas forenses, las investigaciones en torno a la inteligencia artificial y la arqueología, entre otras (Dembski, 1998b: 94).

5 Para una exposición más detallada de este aspecto de la propuesta de Dembski, véase Carreño: 2009, 226-228. 
«creacionismo científico», cuyo propósito no confesado sería el de presentar ciertas creencias religiosas bajo la apariencia de cientificidad, por medio de una gama de falacias ya hace tiempo denunciadas (Pennock, 2003: 143-163; Cornish-Bowden y Cárdenas, 2007: 11 122; Forrest, 2009: 455-462; Boudry, 2010: 473-482).

\section{El papel de Stephen Meyer en el debate en torno a la TDI}

De entre quienes han asumido el desafío de responder a la batería de argumentos con que los objetores han atacado a la teoría del diseño, los que más atención han acaparado son Michael Behe y William Dembski, probablemente debido al papel protagónico que ambos han tenido en la gestación de la teoría. Hay otros autores en esta corriente, no obstante, cuyo pensamiento amerita análisis y comentario. De entre ellos, Stephen Meyer, quizás sea la voz más autorizada de entre los teóricos del diseño en relación al tema del estatuto epistemológico que le correspondería a la teoría en cuestión, aspecto en el que ha desarrollado una línea de pensamiento independiente y en ocasiones discordante de la sostenida por autores como Behe o Dembski. ${ }^{6}$ La estrategia de este autor ha discurrido a través de tres líneas fundamentales. En primer lugar, en una crítica y rechazo a lo que, desde Popper, se conoce como «criterio de demarcación», que consistiría en el intento epistemológico de distinguir, con base en determinadas y estrictas condiciones, lo que es la ciencia de lo que no lo es (Popper, 1994; Schilpp, 1974). De acuerdo con Meyer, tal aproximación carecería de sustento, pues su aplicación conduciría irremediablemente a negarle el estatus de ciencia a teorías y disciplinas que habitual e históricamente han sido tenidas por tales. La consecuencia del descarte de tales criterios, por otro lado, eliminaría buena parte de las críticas epistemológicas que los objetores de la teoría del diseño han levantado contra ella. El segundo aspecto de

6 El aporte de Meyer en los contenidos mismos de la teoría se ha centrado en la aplicación de los criterios de Behe y Dembski a problemas como el asíllamado «ajuste fino del cosmos», y del origen de la información biológica (Meyer, 1998: 114-147; Meyer, 2002: 53-111; Meyer, 2004: 213-239). 
la reflexión de Meyer se ha centrado en la defensa de la TDI contra las abundantes críticas específicas de que ha sido objeto la propuesta desde sus albores, mostrando cómo todas ellas son también aplicables en los mismos términos a las teorías evolutivas -incluyendo entre ellas a la neo-darwinista-, debido a la equivalencia epistemológica que Meyer pretende establecer entre ambos modelos. Finalmente, el autor ha esbozado una tipología epistemológica que, de aceptarse, dejaría un espacio al interior del sistema de las ciencias para teorías como la que él defiende. A continuación expondremos con algún detalle las directrices principales de la TDI, para continuar con una exposición más detallada de estos y otros argumentos adicionales que Meyer ha elaborado en la defensa de la validez epistemológica de la TDI. Concluiremos el artículo con una breve valoración de las limitaciones y aciertos de la estrategia argumentativa del autor.

\section{Ciencia y "pseudo-ciencia»}

Según Meyer, ya Darwin, en las numerosas polémicas que mantuvo con quienes promovían una interpretación literal del libro del Génesis como base para explicar el origen del universo y los vivientes, recurrió en repetidas oportunidades a argumentos epistemológicos para desacreditar a sus adversarios (Meyer, 1994: 69). ${ }^{7}$ Los seguidores de Darwin, afirma Meyer, habrían expandido esta estrategia, atacando todo modelo distinto de las teorías naturalistas de evolución en base en una presunta trasgresión de las normas de la práctica científica, que basadas en una visión positivista y neo-positivista de ella, constituirían en conjunto lo que hoy se conoce como «criterio de demarcación». Pero para Meyer este criterio resulta problemático en sí mismo, y esto por variados motivos.

Por una parte, el intento histórico de encontrar un conjunto de «características invariantes», es decir, de una serie de condiciones

7 Aunque el autor no aporta ninguna cita precisa, efectivamente, tanto en su obra capital como en otros escritos existen pasajes donde Charles Darwin toca cuestiones relativas a la epistemología de su propuesta y de las de otras alternativas con las que disentía (Darwin, 1983: 594-604). 
necesarias y suficientes para distinguir la ciencia de la «pseudo-ciencia», ha fracasado, y estrepitosamente. Más aún, la mayoría de estos argumentos presuponen una comprensión de la actividad científica que refleja la influencia del positivismo lógico; con el creciente rechazo al que se ha visto enfrentada esta doctrina y sus criterios epistemológicos - escribe este autor- la cuestión de la demarcación ha sido también objeto de disputa, no existiendo actualmente un acuerdo respecto a su validez (Meyer, 2002b: 152-153).

Uno de los primeros intentos históricos en esta dirección, según Meyer (quien sigue en sus trazos generales el enfoque de Larry Laudan) fue el así llamado "criterio de la certeza" (Laudan, 1983: 11-128). Según él, la ciencia podría ser distinguida de otras actividades por el grado de certeza de que sus resultados están revestidos. La ciencia produciría certeza, en tanto que otros tipos de búsqueda, tales como la filosofía, conducirían tan sólo a la opinión. Este criterio - continúa Meyer- cayó rápidamente en descrédito a medida que científicos y filósofos se percataron de la naturaleza falible de las disciplinas científicas y sus correspondientes teorías. Se ha objetado, en efecto, que a diferencia de los matemáticos, los científicos rara vez proveen demostraciones estrictamente lógicas en la forma de pruebas deductivas para justificar sus teorías, sino inferencias inductivas y verificaciones predictivas, ninguna de las cuales lleva a la certeza, al menos en términos estrictos y rigurosos. Y desde una perspectiva más histórica, son variados e incluso pintorescos los episodios y anécdotas de la ciencia moderna que han llevado a la filosofía a dudar de la superioridad de su estatus epistémico y a considerar al conocimiento científico, al igual que todo conocimiento humano, como sujeto a la incertidumbre y el error (Meyer, 1994: 70).

Para Meyer, estas y otras falencias del criterio de certeza llevaron las reflexiones de filósofos y científicos del siglo XIX por otras sendas, aun cuando el objetivo de fondo - asegurar la primacía de la ciencia moderna como la forma más elevada y válida de conocimiento- permanecía invariable. Para demostrar la veracidad de tal aserto, los argumentos se basaron ahora en la supuesta superioridad metodológica que la ciencia experimental exhibía en su proceder al ser comparada con otras disciplinas. La ciencia, según tal visión, se venía 
a definir por referencia a su método, que se juzgaba objetivo, riguroso, reproducible y confiable, y que tenía por arquetipo a la física que, a través de sus postulados, sus elegantes hipótesis matemáticamente formuladas y sus finas y precisas verificaciones experimentales, se erigía como el modelo a seguir para toda búsqueda racional de conocimiento que pretendiese ser considerada como científica. Se abría con esto la posibilidad de separar aguas, distinguiendo a la ciencia del dudoso proceder de otras disciplinas, que, por su inevitable dimensión subjetiva, no podían sino constituir una generosa fuente de errores y una etapa cognoscitiva humana en vías de superación.

Sin embargo, dice Meyer, los problemas con este criterio metodológico no tardaron en aparecer. Uno de los más evidentes es la falta de un consenso general con respecto a la naturaleza del método científico y, más aún, sobre si en realidad se puede hablar de un método, en singular, o si, por el contrario, son varias las aproximaciones que podrían cargar con este calificativo. Sobre este punto Meyer es especialmente crítico:

Si los científicos y filósofos no pueden ponerse de acuerdo respecto a lo que es el método científico, ¿cómo pueden descalificar disciplinas que no lo utilicen? [...] La existencia de una variedad de métodos científicos plantea la posibilidad de que ninguna caracterización metodológica de la ciencia pueda bastar para capturar la diversidad de la práctica científica. Usar un conjunto único de criterios metodológicos para establecer el estatus científico podría por tanto resultar en la descalificación de algunas disciplinas antes consideradas como científicas (Meyer, 2002b: 157). ${ }^{8}$

Siguiendo la objeción de Meyer, el cometido de reducir la ciencia al modo de proceder de la física newtoniana no sólo conduciría a una evidente restricción del variado panorama que exhibe la

8 Acto seguido, Meyer afirma que esto no equivale a ninguna clase de anarquismo metodológico, y declara su distancia de autores como Feyerabend, sin explicitar sus divergencias con éste último. El eje de la crítica que Feyerabend esboza respecto a esta cuestión se encuentra en Feyerabend, 2000a; 2000b. 
actividad científica, sino que incluso eliminaría de la física vastos campos y subdisciplinas que no se ajustan al modelo clásico de la física experimental. Para Meyer, estas y otras limitaciones del criterio metodológico habrían mostrado su insuficiencia y la necesidad de un replanteamiento del problema.

Las nuevas propuestas de demarcación, siguiendo el así llamado giro lingüístico o semántico, habrían venido en la segunda década del siglo XX de la mano del positivismo lógico y algunos años más tarde con el criterio de la falsación de Sir Karl Popper (Popper, 1998a: 474-478; 1998b: 228-239; Miller, 1995: 156-197). Con respecto al primero, Meyer repara en la ya célebre antinomia que la misma postulación de dicho criterio conlleva, pues es en definitiva una sentencia filosófica y, como tal, es incapaz de cumplir sus propios estándares de verificación (Meyer, 1994: 70-71). ${ }^{9} \mathrm{Y}$ con respecto al criterio de falsación, Meyer retoma las conocidas críticas que contra él se esbozaron durante la centuria pasada, y que han servido de impulso a propuestas como la de Laudan y Lakatos (Meyer, 1994: 71). Se ha insistido, por cierto, en que rara vez es el núcleo teórico de una teoría el que se ve sometido a la mentada falsación, sino más bien hipótesis auxiliares que dejan lo esencial de la teoría o modelo intocado.

La notoria falla de éstos y otros criterios de demarcación han llevado a Martin Eager a concluir: "Los argumentos de demarcación han colapsado. Los filósofos de la ciencia no los sostienen más. Ellos pueden seguir gozando de aceptación en el mundo popular, pero ese es un mundo diferente" (Meyer, 2002b: 159). El problema, en opinión de Meyer, es que muchos científicos forman parte, muy a pesar de ellos, de ese mundo popular que sigue considerando la distinción de la ciencia con base en algunos de los criterios mencionados como una tarea sencilla y obvia. ${ }^{10}$ En respuesta a estas eventuales objecio-

9 Meyer no profundiza más en este interesante asunto. Para un breve examen, pueden consultarse: Artigas, 1999: 50-53; Gilson, 1962: 49-55.

10 "Sin embargo, -escribe Meyer al respecto- para el científico profesional promedio los argumentos de Laudan contra la demarcación pueden resultar al menos contraintuitivos. En la superficie puede parecer que tiene que haber algún criterio no ambiguo para distinguir tales búsquedas dudosas como la parapsicología, astrología y frenolo- 
nes, afirma Meyer que no es necesario adoptar una visión relativista o antirrealista de la ciencia, sino simplemente aceptar que los criterios, como tales, resultan una herramienta intelectual sumamente precaria para definir y separar lo que se puede denominar ciencia de lo que no.

\section{Las objeciones específicas a la TDI}

Las críticas generales que Meyer esboza y sistematiza contra los criterios de demarcación se tornan más agudas cuando este autor examina las objeciones específicas que, inspiradas en dichos criterios, se han enarbolado contra la TDI. Una de ellas sería la que Michael Ruse, un implacable detractor de la teoría del diseño, ha esgrimido una y otra vez en sus textos y artículos: una actitud auténticamente científica debe aceptar que el universo está regido por leyes naturales, excluyendo, al menos metodológicamente, toda referencia a entidades o agentes no reducibles a dichas leyes. La TDI, entonces, no podría incorporarse en el cuerpo de conocimientos y teorías científicas, toda vez que invoca entidades no naturales en sus explicaciones (Ruse, 1982).

Las respuestas de los teóricos del diseño a esta recurrente objeción han sido variadas y de formalidad y alcance diverso. ${ }^{11}$ La contra-

gía de ciencias establecidas tales como la física, química y astronomía. Que la mayoría de los filósofos de la ciencia digan que no hay tales criterios sólo confirma la sospecha que muchos científicos tienen acerca de la filosofía de la ciencia. Después de todo, ¿no dicen algunos de los filósofos de la ciencia que la verdad científica está determinada por el contexto social y cultural? ¿No niegan algunos incluso que la ciencia describa la realidad objetiva?" (Meyer, 2002: 161).

11 Behe ha afirmado que tal limitación constituye una arbitrariedad filosófica "no contenida en ningún manual o texto científico", y que su aceptación no sería de utilidad alguna, pues no permitiría discriminar la ciencia de la pseudo-ciencia, ni aportaría una definición precisa de la actividad científica (Behe, 2006: 238-243). Dembski, por su parte, en su tono característicamente agresivo, ha denunciado que el establishment darwinista "define la ciencia de tal modo que sólo la evolución naturalista puede constituir una respuesta científicamente válida a la pregunta ¿Cómo se originó y desarrollo la vida?" (1998: 27). Esta limitación, a juicio de Dembski, no sería más que un aforismo profesional, bajo el cual se escondería un naturalismo metodológico, que una vez aceptado, 
argumentación más interesante al criterio naturalista, sin embargo, ha estado nuevamente a cargo de Stephen Meyer. Por una parte, este autor ha argüido que muchas leyes naturales describen regularidades, pero no son estrictamente explicativas, pues no dan cuenta de la razón de dicha regularidad. Un ejemplo clásico de este modo de proceder, para Meyer, está dado por la ley universal de la gravitación que, como el mismo Newton admitió, no explicaba sino sólo describía el movimiento gravitacional. Nuestro autor argumenta que si sólo se admitiesen como científicamente válidas las explicaciones basadas en leyes naturales, esta y otras leyes fundamentales de la física -que según este teórico del diseño no explican, sino que describen matemáticamente el fenómeno considerado- debiesen erradicarse del dominio de lo que habitualmente se considera ciencia. Y, como irónicamente observa Meyer: "Mientras que este resultado pudiese aliviar la «envidia física» de muchos sociólogos, no haría nada por los demarcacionistas, excepto refutar el mismo propósito de su empresa" (Meyer, 2002b: 163). ${ }^{12}$ En efecto, sería aquel un resultado altamente paradójico e indeseado para quienes han esbozado la objeción naturalista contra el DI, sobre todo si se tiene en cuenta que su motivación central ha sido históricamente la de asegurar que todas las disciplinas consideradas como científicas cumplan con los estándares rigurosos de la física. La razón para descartar la teoría del diseño como una conjetura no científica ya no descansaría en que "no explica mediante leyes naturales", sino en que "no recurre a explicaciones naturalistas", y aquí se suma Meyer a las objeciones que autores como Behe y Dembski han esgrimido repetidamente

sólo dejaría espacio a explicaciones materialistas, descartando apriorísticamente hipótesis, modelos y teorías alternativas.

12 No podemos dejar la ocasión de manifestar nuestro desacuerdo con Meyer en este punto. Sus reflexiones no parecen considerar que, en efecto, una ciencia media como la físico-matemática moderna es formalmente matemática pero materialmente física, y que en ella, esa formulación cuantitativa es ya un modo de explicación. Si la búsqueda de causas reales puede ponerse en tela de juicio para la construcción de Ptolomeo, en el caso de Newton esto es difícilmente aceptable. Cierto es que las leyes naturales formuladas por este genial físico no tienen una imagen especular en el mundo, ni abarcan todo el espectro y profundidad de la causalidad constatable en el orden sensible, pero de ello no se sigue que no haya en ellas verdadera ciencia (Casanova, 2007). 
respecto de lo que consideran como una crítica arbitraria contra la teoría del diseño. ${ }^{13}$

Otras objeciones epistemológicas que se han levantado específicamente contra la TDI han centrado su atención en el aspecto metodológico de la propuesta. Según sus críticos, el diseño no sería observable ni verificable, lo que escaparía del esquema hipótesisexperimento-replicación propio de la actividad científica. Esta postura se ilustra claramente en las palabras del biólogo molecular Fred Grinnell, quien ha argumentado que la teoría del diseño no puede ser considerada como científica, porque si algo "—-no puede ser medido, o contado, o fotografiado, no puede haber ciencia” (Grinnell, 1993). Eugenie Scott, llevando las cosas un poco más lejos, ha afirmado: "No puedes usar explicaciones sobrenaturales porque no puedes poner una deidad omnipotente en un tubo de ensayo. Tan pronto como los creacionistas inventen un «teómetro» quizá podamos verificar las intervenciones milagrosas” (Scott, 1994: 30). Más allá del tono polemista y sarcástico de esta última cita, lo que aquí interesa es la esencia de la objeción: dado que el agente diseñador no es detectable mediante los sentidos o los instrumentos científicos, la TDI es por tanto inaccesible a la investigación científica y a la posibilidad de una verificación de acuerdo con los cánones metodológicos que distinguen dicha actividad de otras formas de conocimiento.

Meyer, ampliando la respuesta que Michael Behe había esbozado a dicha objeción, ${ }^{14}$ ha argumentado que la observabilidad no

13 "Por supuesto que el DI no es totalmente naturalista, pero ¿por qué lo hace eso no científico? ¿Qué razón no circular puede ser dada para tal aserto? ¿Qué criterio independiente de método demuestra el estatus científico inferior de una explicación no naturalista? Hemos visto que el «debe explicar mediante ley» no lo demuestra. ¿Qué lo hace?" (Meyer, 2002b: 168).

14 Este autor admite que el diseño no puede ser sometido a verificación experimental, pero otro tanto ocurriría toda vez que la ciencia intenta dar cuenta de eventos históricos únicos, tales como la caída de meteoros ocurrida millones de años atrás, que por definición no son sometibles a pruebas experimentales. Pero así como la ciencia puede ver los efectos presentes del choque de antiguos asteroides en la tierra, también puede observar los efectos que la actividad del diseñador -sea quien sea- ha tenido en los vivientes. Así puesta, la objeción metodológica representaría a los ojos de Behe una restricción inadmisible para la investigación científica, que quedaría confinada a un ámbito determinado de explicaciones, y en definitiva condenada a caer en la dudosa categoría de «más de lo mismo» (Behe, 2006: 243). 
sólo no es aplicable a las ciencias históricas, sino que de hecho está ausente en disciplinas tradicionalmente tenidas por científicas -tales como la física teórica, la biología molecular, la geología, la psicología y la biología evolutiva - en las que lo no observable se infiere a partir de lo observable. Así, entidades tan valoradas en el campo de las ciencias naturales como fuerzas, campos, átomos, quarks, características geológicas de capas profundas de la tierra, estructuras biológicas moleculares, y varias más deberían ser desterradas de los textos científicos con la aplicación estricta y consecuente de este criterio. Además, sigue Meyer, el hecho de que algo no sea observable no impide su verificación. La verificación indirecta de una entidad no observable es posible a través de la evaluación del poder explicativo que resulta si la mencionada entidad se toma como hipotéticamente existente. ${ }^{15}$

Volviendo este argumento contra sus autores - un recurso para el que se ha mostrado especialmente hábil-, dice Meyer que de hecho la TDI y la teoría de evolución por selección natural son equivalentes tanto en su observabilidad como en la posibilidad de ser verificadas empíricamente. Con respecto al primer punto, si bien admite que un diseño escapa a una observación directa, otro tanto ocurre con el proceso evolutivo, que de hecho nadie ha visto en el sentido estricto de la palabra, como tampoco hay testigos oculares de las formas de vida de transición a que dicha reconstrucción apela, que no serían otra cosa que postulados teóricos que hacen posible le explicación evolutiva de los hechos biológicos presentes. E igual cosa ocurre con la posibilidad de una verificación empírica, que tanto para la teoría del diseño como para las teorías evolutivas resulta

15 Como ejemplo de este proceder, cita este autor el caso de la carrera que se dio a mediados del siglo XX para determinar la estructura del ADN; en ella compitieron dos modelos, uno que proponía que el ADN era una doble hélice, y otro que postulaba una triple hélice. Ambas hipótesis podían explicar las imágenes fotográficas producidas por cristalografías de rayos $x, y$ a pesar de que ninguna de las estructuras era directamente observable, la doble hélice de Watson y Crick se impuso finalmente debido a que podía dar cuenta de fenómenos que su rival era incapaz de «salvar». La inferencia de una entidad no observable, concluye Meyer, fue aceptada en este caso porque se juzgó que poseía un mayor poder explicativo que sus competidores con respecto a una variedad de hechos relevantes (Meyer, 1994: 75-77). 
un criterio imposible de cumplir, pues según ya se expuso, no son leyes naturales lo que se intenta describir, sino eventos ocurridos en el pasado a partir de datos o evidencias presentes. Toda teoría de los orígenes es por tanto una teoría histórica, y como tal sólo puede ser verificada indirectamente, a través de la comparación de su poder explicatorio con las teorías, modelos e hipótesis rivales. Concluye el autor:

Aquellos que insisten en el criterio de observabilidad y verificación, concebidos en un sentido positivista, promulgan una definición de la ciencia correcta que la teoría de la evolución manifiestamente no puede cumplir. Si se permite un estándar de verificación menos severo, sin embargo, la razón original para rechazar el diseño se evapora (Meyer, 2002b: 173).

Lamentablemente, Stephen Meyer no le dedica una atención abundante a otros criterios muy socorridos por la literatura epistemológica, y que han sido empleados para arremeter contra la TDI. Así ocurre con el problema de la falsabilidad de la hipótesis del diseño, punto especialmente espinoso y en el que Meyer no se detiene; en efecto, el mismo Dembski ha admitido que descartar que algo haya sido diseñado resulta un problema lógicamente insoluble, dada la posibilidad que tienen las causas inteligentes de imitar procesos naturales (Dembski, 2002: 35). Otro tanto puede decirse de la ausencia de mecanismos causales que algunos críticos le han impugnado a la teoría en cuestión, y que Meyer descarta denunciando la filosofía materialista que a su juicio subyace bajo tales ataques (Meyer, 1994: 72).

Mención aparte merece la crítica planteada a la capacidad predictiva de la TDI, argumento estrechamente vinculado con el poder explicativo de la propuesta. Por cierto, uno de los atributos que más poderosamente han jugado a favor de la teoría sintética es el hecho de que sobre la base de un mecanismo simple, es posible dar cuenta, al menos verosímilmente, de un cúmulo significativo de hechos y eventos. ¿Puede decirse lo mismo de la TDI? Como lo mencionábamos en la introducción, Michael Behe y William Dembski han admitido que la inferencia de diseño es una opción de exclusión, sólo 
atendible una vez que se hayan descartado otras formas de explicación. Si es así, ¿no pasa a constituir el diseño, más que una teoría, una hipótesis sólo excepcionalmente invocable? Meyer no parece reparar en la dificultad, al menos no explícitamente. No puede decirse lo mismo, sin embargo, de la crítica a la capacidad predictiva de la TDI; de acuerdo con el autor, por su misma textura epistemológica, las teorías de los orígenes están confinadas a ofrecer reconstrucciones ex post facto, quedando la proyección de sus resultados en el tiempo fuera de su esfera explicativa (Meyer, 1994: 72). ${ }^{16}$ Este punto nos conduce al meollo de la tesis de Stephen Meyer, a saber, su postulación de la TDI como teoría científico-histórica.

\section{LaTDI como ciencia histórica}

De entre los teóricos del diseño, algunos autores no dudan en catalogar a la TDI de científica, con una argumentación basada en la crítica a los presupuestos materialistas sobre los que descansaría la difundida opinión de que la ciencia debe versar acerca de causas y fenómenos naturales. ${ }^{17}$ Stephen Meyer, en cambio, ha pretendido

16 Otro defensor de la teoría se ha referido recientemente a este punto, aunque de un modo no del todo satisfactorio, a nuestro modo de ver (Ratzsch, 2010: 345-346).

17 Entre estos puede contarse, sin lugar a dudas, a Michael Behe. Según este autor, la simple y poderosa idea del DI sería el resultado de décadas de trabajo acerca de las bases moleculares de la vida, y bien puede considerarse como uno de los resultados más relevantes en la historia de la ciencia (Behe, 2006: 232-253). Paul Nelson, otro teórico del diseño interesado en la epistemología de la propuesta, ha centrado su argumentación en la defensa del aspecto propositivo del DI contra quienes lo tildan de ser una mera suma de objeciones a teorías alternativas, o como una simple apelación al «God of the gaps». Afirma este autor que la propuesta a la que adhiere es «ciencia ordinaria», por lo que el «mito filosófico» de que correspondería a un conocimiento negativo -una teoría de la ignorancia-, no sería sino la consecuencia de una «falla masiva» en nuestro modo de razonar, falla que habríamos heredado del naturalismo del siglo xix. Por el contrario, este autor ve en la teoría del diseño una explicación positiva y robusta, alcanzada por métodos ordinarios de inferencia y formalizada por el criterio de complejidad-especificación y el filtro explicatorio de Dembski, y que como tal, no adolecería de inconvenientes lógicos o metodológicos más allá del ya célebre problema de la inducción planteado hace décadas por Popper, transversal a "toda búsqueda racional y por tanto objetable a cualquiera en general y nadie en particular" (Nelson, 1998: 149). 
llevar la discusión más allá de los criterios demarcacionistas clásicos, para lo cual introduce algunos criterios epistemológicos que vale la pena comentar. Según este autor, la falla de muchos críticos y aún de varios teóricos del diseño en precisar el tipo epistemológico que le correspondería a la TDI residiría en una limitada comprensión de la actividad científica y de la pluralidad de aproximaciones teóricas que bajo tal rótulo se cobijan. Esta diversidad puede según Meyer agruparse en dos grandes categorías de ciencias, a saber, las «nomológicas» o inductivas y las históricas. Las primeras, según Meyer, tienen por principal afán el conocimiento de la operación o «funcionamiento normal» de la naturaleza, objetivo que se llevaría a cabo mediante el descubrimiento, clasificación y explicitación de leyes y propiedades naturales. En estas disciplinas se utiliza una lógica típicamente inductiva -infiriéndose generalizaciones a partir de hechos singulares-y las explicaciones están basadas en descripciones o teorías de fenómenos generales.

Las disciplinas comprendidas en la segunda categoría, las así llamadas ciencias históricas - entre las cuales cuenta la cosmología, la arqueología, la geología histórica, la física y la química aplicada, los estudios del origen de la vida y la biología evolutiva- tienen por objeto eventos o hechos particulares, para lo cual dependen primariamente, y aún exclusivamente de la especificación de condiciones causales ocurridas en el pasado, y no de leyes. Estas disciplinas, por lo tanto, se distinguirían por buscar la reconstrucción de eventos pretéritos a partir de datos o hechos presentes, para lo cual se utilizaría una lógica «abductiva» $\mathrm{o}$ «retrodictiva», caracterizada por una asimetría temporal, o como dice Meyer, citando a su vez a Gould, “infiriendo la historia a partir de sus resultados" (Gould, 1986: 61). Así, en las ciencias históricas citar un evento causal pasado explica a menudo más satisfactoriamente un fenómeno determinado que una referencia a una ley o regularidad de la naturaleza. La razón de esto, -continúa Meyer- está en que muchos eventos particulares vienen a la existencia a través de una serie de eventos previos que no volverán a ocurrir regularmente. No habiendo una regularidad, mal podría haber una ley en el sentido aquí considerado, que no es otra cosa que la expresión matemáticamente formulada de dicha regularidad. 
En las ciencias históricas, a diferencia de las nomológicas, son los eventos causales pasados y no las leyes naturales las entidades que hacen el «trabajo explicativo primario», y su verificación procedería de manera indirecta, a través de la comparación del poder explicativo de teorías rivales:

los argumentos de demarcación parecen fallar -afirma Meyer-, al menos en parte porque intentan imponer (como normativos) criterios de método que ignoran el carácter histórico de la investigación de los orígenes. Indudablemente, cada uno de los argumentos demarcacionistas antes enlistado falla porque obvia una característica específica de las ciencias históricas (Meyer, 2002b: 178).

Nótese que bajo el rótulo de «investigación de los orígenes» caben en opinión de Meyer tanto las diversas teorías de evolución naturalistas como la del DI, de acuerdo con la equivalencia epistemológica que establece este autor entre ambas propuestas. El rechazo, por lo tanto, de la TDI como explicación científicamente válida sobre la base del criterio de Ruse debería conducir, según Meyer, a un simultáneo descarte de las teorías evolutivas. Con el fin de ilustrar su argumentación, analiza Meyer la teoría de evolución por selección natural a la luz de las mencionadas características de lo que el denomina «ciencias históricas», mostrando el explícito interés histórico de dicha propuesta, los razonamientos «abductivos» o «retrodictivos» que caracterizan sus inferencias, el modo de explicación basado en eventos causales pasados y la clase de verificación indirecta que la sostiene, fundamentada sobre todo en su poder explicativo (Meyer, 1994: 79). Siguiendo estos lineamientos, muestra Meyer cómo cada una de las notas propias de las ciencias históricas se cumplen a cabalidad en la TDI. Acto seguido, sugiere Meyer que si se acepta que existe un patrón de investigación histórico, en el que tienen cabida disciplinas tradicionalmente tenidas por científicas, entre ellas, la biología evolutiva y la TDI, "puede haber un sentido legítimo aunque 
convencional en el cual el diseño puede ser considerado científico" (Meyer, 2002b: 178). ${ }^{18}$

Basándose en esta distinción entre ciencias nomológicas e históricas, Meyer ha intentado aplacar los temores de aquellos que ven en la aceptación de la TDI una amenaza para la práctica científica. ${ }^{19}$ Según estos críticos, aceptar los planteamientos del DI supondría según sus críticos- una esterilización de las ciencias naturales, toda vez que la búsqueda de causas naturales para los fenómenos y regularidades observables en el universo físico podría verse reemplazada por el recurso constante al diseño. Esto explica el rechazo furibundo que en ciertos círculos ha concitado la postulación de la TDI como una alternativa válida a las teorías evolutivas: estos apasionados detractores ven en la mencionada propuesta un atentado directo a la ciencia y un germen de irracionalismo que amenaza contaminar la esencia misma de nuestra cultura.

Para Meyer, estos pronósticos negativos serían infundados, pues mientras el recurso al diseño puede servir como una explicación legítima en las ciencias históricas, no tendría cabida en las nomológicas o inductivas. En estas últimas, dice Meyer, la pregunta esencial es qué hace la naturaleza normalmente, o cómo una parte de ella afecta a otra, por lo que la respuesta debe ser necesariamente naturalista. Invocar un agente diseñador o un mecanismo evolutivo para dar cuenta del efecto de la presión atmosférica sobre la formación de cristales, simplemente fallaría en proveer la explicación que la interrogante busca. Este tipo de respuestas, por tanto, no sólo violaría las reglas propias de la investigación científica, sino las del sentido común, que siempre debe tener en consideración el contexto y la perspectiva en

18 Anticipándose a las objeciones que podrían venir, admite Meyer: "quizá, sin embargo, simplemente no se quiera llamar al diseño inteligente una teoría científica. Quizá uno prefiera la designación de «especulación histórica cuasi-científica con fuertes notas metafísicas». Muy bien. Llámesela como se quiera, asegurando que el mismo nombre va a ser aplicado a otras formas de investigación que tienen el mismo carácter y las mismas limitaciones metodológicas y lógicas" (Meyer, 2002b: 178).

19 David Hull ha manifestado en términos algo imprecisos esta actitud: “Los científicos no tienen elección. Una vez que ellos permiten la referencia a Dios o a fuerzas milagrosas para explicar el origen de la vida o la evolución de la especie humana, no tienen manera de limitar este tipo de explicación" (Hull, 1991: 485-486). 
que una pregunta ha sido planteada. Pero de ahí no se sigue, argumenta Meyer, que la explicación con base en un diseño sea inapropiada en todo dominio. Por el contrario, la postulación de la acción pasada de un agente en las ciencias históricas es apropiada porque coincide con la búsqueda misma que mueve a estas disciplinas.

Una prueba de esto es que la acción de agentes inteligentes es rutinariamente invocada para dar cuenta de los orígenes de características o eventos en el mundo natural, como de hecho sucede en las ciencias forenses, en la historia y en la arqueología. La existencia de estas disciplinas constituye un claro precedente, a juicio de Meyer, para inferir la actividad causal pasada de agentes inteligentes en el contexto epistemológico de las ciencias históricas (Meyer, 1994: 8284). Según la tesis de Meyer, entonces, la invocación de diseño no sólo está limitada fundamentalmente a las ciencias históricas -quedando vedado un vasto ámbito dentro de las ciencias nomológicas-, sino que su uso también estará restringido en el campo de las explicaciones históricas, donde la competencia con teorías rivales dará lugar a la mejor explicación, es decir, prevalecerá la teoría, hipótesis o modelo que dé cuenta de la mayor cantidad de datos presentes.

Apoyándose en el filtro explicatorio de Dembski, dice Meyer que si bien el DI podría causar todo tipo de efectos, no puede ser invocado para explicar todo tipo de efectos, sino solo aquellos eventos de baja probabilidad y especificados. Aunque otros eventos de alta, intermedia o baja probabilidad también pudieron haber sido la consecuencia del diseño de un agente inteligente, la posibilidad de que obedezcan a leyes naturales o al simple azar impide inferir un diseño con certeza. Concluye por tanto Meyer:

Al menos para aquellos científicos que buscan la mejor explicación, el diseño inteligente no puede ser invocado como una teoría del todo. Podría funcionar como una posible teoría del todo, pero puede funcionar como la mejor explicación o la mejor teoría de sólo algunas cosas. El diseño inteligente no requiere ser vacío o ilimitado (Meyer, 2002b: 189). 
Además de las razones netamente epistemológicas que esgrime Meyer para responder las objeciones de los críticos del diseño en relación con el efecto negativo que esta teoría tendría en el contexto de las ciencias naturales, también existirían motivos metafísicos y teológicos por los que estos reparos pueden ser desestimados. La mayoría de los teístas bíblicos - según este autor-asumen que Dios actúa en el mundo al menos de dos modos: (i) a través de las regularidades o leyes naturales que Él mantiene y sustenta por su poder invisible; (ii) a través de acciones más dramáticas, discernibles y discretas en puntos precisos del tiempo. Debido a que el segundo modo de actuar divino es considerado como el más excepcional, y generalmente asociado con propósitos particulares, nos dice Meyer que los "teístas generalmente se aproximan al estudio de la naturaleza con un conjunto de suposiciones de base que los llevaría a descartar la mayoría de las hipótesis de acción especial divina como poco probables, aunque no completamente imposibles" (Meyer, 2002b: 190).

Un ejemplo que el autor nos proporciona de esta actitud consistiría en el rechazo generalizado que en su momento produjo el postulado de Newton de una intervención divina especial para estabilizar el movimiento orbital de los planetas Júpiter y Saturno. Tal modo de acción fue visto por no pocos teólogos, filósofos y científicos como contrario a la inteligencia y poder infinitos del Creador, que en lugar de hacer un universo regular y ordenado, se veía obligado a corregir permanentemente los errores y defectos que en él surgían. Contrariamente a los objetores del DI -que frecuentemente citan este episodio como una prueba de que el diseño no tiene cabida en el contexto de la ciencia empírica-sostiene Meyer que tal experiencia muestra claramente que una TDI se vería restringida en sus alcances en el contexto de las ciencias nomológicas no sólo por motivos epistemológicos, sino también metafísicos y teológicos.

\section{Conclusión}

Si autores como Behe y Dembski han desempeñado un papel relevante en la elaboración misma de la TDI, no ocurre lo mismo con la 
reflexión en torno a la identidad de la propuesta, tema en el cual sus argumentos han sido frecuentemente tachados -las más de las veces con razón-de simplistas e ideologizados (Pennock, 2001: 16-19; Peterson, 2002: 7-23; Shanks, 2004;Young, 2004). Es en este ángulo de la cuestión en la que cabe catalogar los esfuerzos de Stephen Meyer, autor perteneciente a una segunda generación de teóricos del diseño, no tan preocupados por construir una alternativa frente al darwinismo, como sus predecesores, sino más bien por defenderla y sostenerla como una opción intelectualmente válida frente a la miríada de ataques de que ha sido objeto. El trabajo de este autor ha sido frecuentemente omitido en las revisiones y artículos especializados en relación con la TDI, lo que empobrece significativamente la discusión y análisis de los varios pormenores que se entretejen en esta cuestión.

Para el propósito de valorar la especulación de Meyer, tanto en sus aciertos como en lo que consideramos sus aristas más falentes, parece oportuno seguir de cerca la esquematización antes ofrecida de su trabajo. El análisis que este autor nos proporciona de lo que denomina genéricamente como «criterio demarcacionista» aparece como el punto más débil de su trabajo. De un modo algo expeditivo y carente de matices, Meyer pasa revista a una serie de problemas extremadamente complejos y repletos de cuestiones de detalle, tomando como indubitables las conclusiones que Laudan, mucho más cauto y prolijo, ha trabajado en una copiosa obra (Laudan, 1976; $1977 ; 1981 ; 1986 ; 1990 ; 1996)$. En el fragor de dicho examen, Meyer parece desdibujar todos los contornos del debate contemporáneo en filosofía de las ciencias, sumiéndose en un convencionalismo epistemológico por momentos superficial, que permea a las respuestas que el autor proporciona a las objeciones epistemológicas específicas que se han levantado contra el diseño.

En efecto, la falta de precisión y fineza en su análisis lo conduce a afirmar, en uno de sus giros más controversiales, una suerte de paridad entre la TDI y las teorías evolutivas en términos de su estatuto epistemológico. Más allá de las similitudes que entre las teorías evolutivas y la TDI puedan a juicio de Meyer establecerse, resta en nuestra opinión una diferencia evidente: mientras las primeras emplean en sus interpretaciones una perspectiva - una ratio formalis objecti 
ut objectum, según la terminología clásica $-{ }^{20}$ finalmente referida a hechos empíricamente constatables, la TDI recurre en sus reconstrucciones a un tipo de explicación denominada «diseño». En principio no habría inconveniente en ello, siempre y cuando la noción de «diseño» hubiese sido reformulada y adaptada para constituir un léxico apropiado al contexto epistemológico de que tratamos, y con ella se hiciese referencia a un determinado proceso natural, esto es, empíricamente constatable en el presente. Pero esto es justamente lo que no ocurre en la TDI. La interpretación histórica que los teóricos del diseño proponen para explicar la aparición de determinados aspectos del universo físico descansa finalmente en la falla de otras alternativas, en particular, de la darwinista. No se postula una reconstrucción del pasado cuya plausibilidad sea susceptible de constatación directa o indirecta en el presente, sino que se recurre al «diseño» ahí donde otras alternativas parecen fracasar, y, en ese sentido, constituye un modo negativo de explicación, o si se quiere, una opción de descarte. ${ }^{21}$ Creemos que justificar tal proceder, como estos autores lo hacen, sobre la base de que así procedemos en nuestra vida diaria constituye un recurso de valor retórico, pero no científico ni menos aún filosófico.

La vertiente más sugerente (aunque no del todo original) ${ }^{22}$ de la intervención de Stephen Meyer en el debate epistemológico

20 Ha sido Jacques Maritain quien ha rescatado esta terminología escolástica para su aplicación a los problemas epistemológicos modernos. Con el fin de adaptarlo a los usos actuales, también denomina a esta ratio formalis objecti ut objectum como «luz objetiva», y al objeto formal quo especificativo que de ella resulta como «esfera de inteligibilidad de segunda determinación» (Maritain, 1967: 159-160; Maritain, 1968: 238-249).

21 Pensamos que esta deficiencia no autoriza, sin embargo, a denominar a la TDI de «teoría de la ignorancia» o de «creacionismo retocado», como algunos lo han planteado. Lo que aquí pretendemos mostrar es que, si bien la TDI posee un aspecto constructivo, el núcleo de dicho aspecto resulta epistemológica y explicativamente deficitario, y por tanto, termina siendo subsidiario de otras teorías y modelos, que paradójicamente, son justamente las que pretende refutar.

22 Cabe mencionar que desde las mismas ciencias naturales, autores como Stephen Jay Gould han sostenido visiones semejantes respecto al estatuto que a la teoría darwinista le compete desde un punto de vista epistemológico (Gould, 1986: 61). Para trabajos más recientes en relación con este problema: Dodick y Orion, 2003: 197-211; Inkpen y Wilson, 2009: 329-334; Cleland, 2011: 551-582; Tucker, 2011: 805-829. 
suscitado a raíz de la aparición de la TDI radica en la distinción que avanza entre lo que denomina como ciencias nomológicas o inductivas y las históricas o retrodictivas. Se trata, ciertamente, de un intento serio por trascender el mero proselitismo e iniciar un examen detenido de la propuesta del diseño y de la identidad que le compete en el mapa de los saberes. Este mérito, lamentablemente, se ve opacado por las insuficiencias y parcialidades de la caracterización que Meyer hace de las ciencias, especialmente de las históricas, que son las que aquí nos atañen más directamente. Si bien las notas que él menciona como distintivas de tal disciplina son a nuestro juicio acertadas si se toma la aproximación histórica genéricamente, fallan no obstante en precisar la especificidad que corresponde a las disciplinas que pretende perfilar. En estos saberes la motivación histórica tiene por objeto un tipo peculiar de eventos pasados, los referidos al ens mobile, seres sometidos al devenir, y la función explicativa recae asimismo sobre lo que hemos denominado «procesos naturales». $\mathrm{Al}$ omitir estas especificidades metodológicas, Meyer no termina de establecer adecuadamente este tipo epistemológico, y eso quizá lo lleva a concluir, incorrectamente, que la TDI tiene plena cabida en tal dominio del saber. En apoyo de nuestra postura, recalcamos que han sido los mismos teóricos del diseño - entre ellos Meyer- quienes han admitido que su planteamiento no observa el naturalismo metodológico que sí se ve en las diversas variantes de teorías evolutivas gradualistas; probablemente esta sea la razón de los enconados debates y polémicas que los defensores de una y otra postura han sostenido, y que en cambio no se observan, -al menos no con ese antagonismo acérrimo- entre los adherentes a la teoría de la evolución por selección natural y los que optan por el modelo de evolución por equilibrio puntuado de Gould. Hay entre estos últimos un acuerdo tácito acerca del tipo de reconstrucciones históricas válidas en este ámbito epistemológico. Este acuerdo no descansa necesariamente en un materialismo metafísico compartido (aunque per accidens pudiese ser así), sino en un naturalismo metodológico explícita o implícitamente aceptado, aun cuando discrepen en los contenidos mismos de las interpretaciones que cada alternativa postulará para dar cuenta del origen y devenir de los vivientes. Ambos son modelos 
históricos, o como preferimos designarlos, histórico-naturales, ${ }^{23} \mathrm{y}$ podrán rivalizar legítimamente en cuanto a lo que Meyer denomina sus respectivos «poderes explicativos».

Tampoco nos parecen afortunadas las afirmaciones de Meyer respecto al control que la teología y la metafísica llevarían a cabo sobre la hipótesis del diseño. Si metafísicos y teólogos deben pronunciarse respecto a los contenidos de una determinada teoría que pretende ser tenida por científica, ¿qué mejor prueba de que tal propuesta ha traspasado las fronteras de sus dominios? No vemos motivo para que la metafísica y la teología se inmiscuyan en temas de la competencia de la ciencia natural, salvo que la propuesta misma, o las extrapolaciones que de ella se hagan, toquen asuntos que justifiquen una aclaración fundamental y explícita. Un excelente ejemplo de esta situación nos lo brinda el mismo Meyer, al citar el rechazo que la hipótesis newtoniana acerca de una corrección divina de la órbita de Saturno concitó entre científicos, filósofos y teólogos de la época (Meyer, 2002b: 191-192). Si bien la intención del teórico del diseño es ilustrar cómo las concepciones teológicas y filosóficas podrían contener el recurso indiscriminado a la apelación a un diseño en el contexto de las ciencias naturales, pensamos, por el contrario, que el caso histórico traído a colación es más bien un ejemplo del que debiéramos obtener enseñanzas muy distintas. No vemos en dicha situación, como Meyer pretende, un uso específicamente ilegítimo del recurso a un agente inteligente, sino más bien el arquetipo de una trasgresión epistemológica, que ha conducido a un científico (y uno de los más geniales de la historia, por cierto) a invocar tipos de explicación que no tienen cabida en la disciplina que cultiva. Si este error, oportunamente detectado y enmendado, puede disculparse en Newton en consideración de su situación histórica, creemos que

23 Con esto no queremos afirmar la veracidad de ninguna de las teorías evolutivas traídas a colación -tópico que escapa a las pretensiones de este trabajo-, sino afirmar su validez desde una perspectiva estrictamente epistemológica. En efecto, un modelo o hipótesis puede estar en perfecta armonía con los cánones que configuran un determinado ámbito del saber humano, y no ajustarse, sin embargo, a la realidad, o hacerlo sólo parcialmente. 
hoy, a más de tres siglos de tales sucesos, ya contamos con la experiencia necesaria como para evitar traspiés semejantes.

\section{Referencias bibliográficas}

Artigas, M. (1999). Filosofía de la ciencia experimental. Pamplona: EUNSA.

Gilson, E. (1962). El filósofo y la teología. Madrid: Ediciones Guadarrama.

Behe, M. (2006). Darwin's Black Box: The Biochemical Challenge to Evolution. New York: The Free Press.

. (2009). "Irreducible Complexity: Obstacle to Darwinian Evolution”. En A. Rosenberg y A. R. Robert (eds.) Philosophy of Biology: An Anthology, WestSussex: Wiley-Blackwell.

Boudry, M.; S. Blancke; J. Braeckman. (2010). "Irreducible Incoherence and Intelligent Design: A Look into the Conceptual Toolbox of a Pseudoscience”. En The Quarterly Review of Biology, v. 85 (4), 473-482.

Carreño, J. E. et al. (2009). "Some Considerations about the Theory of Intelligent Design”. En Biological Research 42, 223-232.

Casanova, C. (2007). Reflexiones metafísicas sobre la ciencia natural. Santiago: Ril.

Cleland, C. (2011). "Prediction and Explanation in Historical Natural Science". En The British Journal of the Philosophy of Science, 62 (3), 551-582.

Cornish-Bowden, A.; M. L. Cárdenas (2007). "The Threat from Creationism to the Rational Teaching of Biology”. Biological Research 40, 113-122.

Darwin, C. (1983). El origen de las especies. Madrid: Altamira.

Dawkins, R. (1996). The BlindWatchmaker. London: W.W. Norton.

Dembski, W. (1998a). "Introduction”. En W. Dembski (ed.) Mere Creation. Downers Grove: InterVarsity Press.

. (1998b). "Redesigning Science". En W. Dembski (ed.) Mere Creation, Downers Grove: InterVarsity Press.

(1998c). The Design Inference: Eliminating Chance through Small Probabilities. Cambridge: Cambridge University Press.

. (2002). "The Third Mode of Explanation: Detecting Evidence of Intelligent Design in the Sciences”. En: M. Behe; W. Dembski; S. Meyer (eds.). Science and Evidence for Design in the Universe. San Francisco: Ignatius Press.

. (2004). The Design Revolution: Answering the Toughest Questions about Intelligent Design. Downers Grove: InterVarsity Press. 
Dodick, J.; N. Orion. (2003) "Geology as an Historical Science: Its Perception within Science and the Education System”. En Science \& Education 12, 197-211.

Feyerabend, P. (2000a). Diálogo sobre el método. Madrid: Cátedra. . (2000B). Tratado contra el método. Madrid: Tecnos.

Forrest, B. (2009). “The Religious Essence of Intelligent Design”. En Cold Spring Harbor symposia on quantitative biology, 74: 455-462.

Gould, S. J. (1986). "Evolution and the triumph of homology: or why history matters”. En American Scientist, Vol. 74, 61. (2004). La estructura de la teoría de la evolución. Barcelona: Tusquets.

Grinnell, F. 1993. "Radical intersubjectivity: why naturalism is an assumption necessary for doing science", trabajo presentado en conferencia en la Southern Methodist University, Dallas.

Hull, D. 1991. "God of the Galápagos”. En Nature, Vol. 352, 485-486.

Inkpen, R; G. Wilson. (2009). "Explaining The Past: Abductive and Bayesian Reasoning”. En The Holocene, vol. 2, 329-334.

Johnson, PE. (1993). Darwin on Trial. Downers Grove: InterVarsity Press.

. (1998). Reason in the Balance. Downers Grove: InterVarsity Press.

(2002). The Right Questions. Downers Grove: InterVarsity Press.

Jones III, J. 20 de Diciembre, 2005. Kitzmiller v. Dover Area School Distric.

Laudan, L. (1976). “Two Dogmas of Methodology”. En Philosophy of Science v. 43, 587-597.

. (1977). Progress and its Problems. Toward a Theory of Scientific Grow. Berkeley: University of California Press.

. (1981). Science and Hypothesis. Dordrecht: Reidel.

(1986). Science andValues. Berkeley: University of California Press.

Press.

(1990). Science and Relativism. Chicago: The University of Chicago

(1996). Beyond Positivism and Relativism. Boulder: Westview Press.

(1983). The Demise of the Demarcation Problem. En Physics, Philosophy and Psychoanalysis. R. Cohen \& L. Larry, eds. Dordrecht: Reidel.

Maritain, J. (1967). Filosofía de la naturaleza. Buenos Aires: Club de Lectores.

(1968). Los grados del saber. Buenos Aires: Club de Lectores.

Meyer, S. (1994). The Methodological Equivalence of Design \& Descent: Can There Be a Scientific "Theory of Creation"? En The Creation Hypothesis: Scientific Evidence for An Intelligent Design, ed. Porter, James. Downers Grove, InterVarsity Press. 
(1998). “The explanatory power of design”. En Behe, M. et al. Mere Creation. D. Berlinski, P. Johnson, eds. Downers Grove: InterVarsity Press.

. (2002a). "Evidence for design in physics and biology: from the origin of the universe to the origin of life". En: Behe, M. et al. Science and Evidence for Design in The Universe. ed. D. Berlinski, P. Johnson, eds. San Francisco: Ignatius Press.

(2002b). The scientific status of intelligent design: the methodological equivalence of naturalistic and non-naturalistic origins theories. En: Behe, M. et al. Science and Evidence for Design in The Universe. ed. D. Berlinski, P. Johnson, eds. San Francisco: Ignatius Press.

. (2004). "The origin of biological information and the higher taxonomic categories". En The proceedings of the biological society of Washington, Vol. 117, n. 2, 213-239.

Miller, D. (1995). Popper escritos selectos. Ciudad de México: Fondo de Cultura Económica.

Nelson, P. (1998). Applying Design Within Biology. En Behe, M. et al. Mere Creation. D. Berlinski, P. Johnson, eds. Downers Grove: InterVarsity Press.

Pennock, R. (2001). “Whose God? What Science?: Reply to Michael Behe”. En Reports of the National Center for Science Education, Vol. 21, n. 3-4, 16-19.

. (2003). “Creationism and Intelligent Design”. En Annual Review Genomics Human Genetics, Vol. 4, 143-163.

Peterson, G. (2002). “The Intelligent Design Movement: Science or Ideology?”. En Zygon vol. 37, no. 1, 7-23.

Popper, K. (1994). Búsqueda sin término. Una autobiografía intelectual. Madrid: Tecnos.

. (1998). "Esbozo de una teoría del método científico-empírico (teoría de la experiencia)”. En: Los dos problemas fundamentales de la epistemología. T. Eggers, ed. Madrid: Tecnos.

(1998). Conjectures and Refutations. The Growth of Scientific Knowledge. London: Routledge.

Ratzsch, D. (2010). “There is a Place for Intelligent Design in Philosophy of Biology”. En: Contemporary debates in philosophy of biology, ed. Ayala, Francisco, ARP, Robert. West- Sussex, Wiley-Blackwell.

Ruse, M. (1982). Darwinism Defended: A Guide to The Evolution Controversies. London: Addison-Wesley.

Schilpp, P. (1974). The Philosophy of Karl Popper. La Salle: Open Court Press.

Scott, E. (1994). “Keep Science Free from Creationism”. En Insight, 30.

Shanks, N. (2004). God, The Devil and Darwin: A Critique of Intelligent Design Theory. Oxford: Oxford University Press. 
Tucker, A. (2011). "Historical Science, Over- and Underdetermined: A Study of Darwin's Inference of Origins". En The British Journal of the Philosophy of Science, Vol. 62, n. 4, 805-829.

Young, M; Talner, eds. (2004). Why Intelligent Design Fails. A Scientific Critique of The New Creationism. M.Young \& Talner, eds. New Jersey: Rutgers University Press. 